\title{
Stable Continuous Production of $\gamma$-Valerolactone from Biomass-Derived Levulinic Acid over Zr-Al-Beta Zeolite Catalyst
}

\author{
Clara López-Aguado ${ }^{1}$, Marta Paniagua ${ }^{1}{ }^{\mathbb{C}}$, Juan A. Melero ${ }^{1}{ }^{\mathbb{C}}$, Jose Iglesias ${ }^{1}{ }^{\mathbb{D}}$, Pablo Juárez ${ }^{1}$, \\ Manuel López Granados ${ }^{2}$ and Gabriel Morales ${ }^{1, *(D)}$ \\ 1 Chemical and Environmental Engineering Group, Escuela Superior de Ciencias Experimentales y \\ Tecnología (ESCET), Universidad Rey Juan Carlos, C/Tulipán s/n, Móstoles, E28933 Madrid, Spain; \\ clara.lopezaguado@urjc.es (C.L.-A.); marta.paniagua@urjc.es (M.P.); juan.melero@urjc.es (J.A.M.); \\ jose.iglesias@urjc.es (J.I.); pablo.juarez@urjc.es (P.J.) \\ 2 Energy and Sustainable Chemistry (EQS) Group, Institute of Catalysis and Petrochemistry, CSIC, \\ Marie Curie 2, Campus de Cantoblanco, 28049 Madrid, Spain; mlgranados@icp.csic.es \\ * Correspondence: gabriel.morales@urjc.es; Tel.: +34-91-488-80-91
}

Received: 20 May 2020; Accepted: 15 June 2020; Published: 17 June 2020

\begin{abstract}
The one-pot conversion of biomass-derived platform molecules such as levulinic acid (LA) and furfural (FAL) into $\gamma$-valerolactone (GVL) is challenging because of the need for adequate multi-functional catalysts and high-pressure gaseous hydrogen. As a more sustainable alternative, here we describe the transfer hydrogenation of LA to GVL using isopropanol as a hydrogen donor over a Zr-modified beta zeolite catalyst in a continuous fixed-bed reactor. A stable sustained production of GVL was achieved from the levulinic acid, with both high LA conversion (ca. 95\%) and GVL yield (ca. 90\%), for over at least 20 days in continuous operation at $170{ }^{\circ} \mathrm{C}$. Importantly, the small decay in activity can be advantageously overcome by the means of a simple in situ thermal regeneration in the air atmosphere, leading to a complete recovery of the catalyst activity. Key to this outstanding result is the use of a $\mathrm{Zr}$-modified dealuminated beta zeolite with a tailored Lewis/Brønsted acid sites ratio, which can synergistically catalyze the tandem steps of hydrogen transfer and acid-catalyzed transformations, leading to such a successful and stable production of GVL from LA.
\end{abstract}

Keywords: biomass valorization; levulinic acid; $\gamma$-valerolactone (GVL); zirconium; beta zeolite; fixed bed; continuous flow

\section{Introduction}

Due to increasing environmental impacts and to the depletion of fossil resources, there is a pressing interest to search and develop renewable alternatives. In this context, biomass attracts much attention for the production of both fine chemicals and fuels [1-5]. As a result, many processes have been proposed and developed for the conversion of biomass in recent years [2,6]. Particularly, lignocellulosic biomass is considered a promising, worldwide-abundant, and carbon-neutral resource. However, the production at the industrial scale of the added-value chemicals from biomass requires intensive efforts in the design, development and intensification of cost-effective catalytic processes, within the concept of biomass refinery [7-14]. One efficient route to convert lignocellulose into high-quality fuels and chemicals initiates the hydrolytic deconstruction at relatively mild temperatures $\left(150-250{ }^{\circ} \mathrm{C}\right)$, producing levulinic acid (LA) and furfural, as two of the most relevant lignocellulose-derived platform molecules [15-17]. Levulinic acid has been recognized as one of the top 10 most promising platform molecules derived from biomass by the U.S. Department of Energy [18], currently being considered as a key pillar in the upcoming biorefinery industry as a chemical intermediate to many other bio-based 
compounds [19]. On the other hand, furfural has been catalogued as among the top 30 platform chemicals derived from biomass, also with a great potential in many distinct fields [20]. However, such biomass platform molecules have a high oxygen content and various functional groups, making any transformational route typically complex and nonselective [8]. Therefore, the development of efficient strategies to transform these platform molecules is highly desirable for producing high-quality fuels and chemicals. On the industrial scale, several companies all over the world have developed industrial-scale processes for the production of levulinic acid and furfural, focusing on feasible commercial applications of levulinic acid, such as lactones, levulinate esters, aminolevulinic acid, or valeric biofuels [21,22].

One promising application of LA is for the production of $\gamma$-valerolactone (GVL), a molecule that exhibits attractive physicochemical properties, such as biodegradability and low toxicity, as well as excellent fuel characteristics. Thus, GVL has potential as a green solvent, gasoline additive, or precursor for the production of food additives, bio-polymers, advanced biofuels, etc. [23-27]. Many heterogeneous catalysts, especially based on the use of noble metals (e.g., ruthenium [28,29], gold [30]), have successfully catalyzed the transformation of LA or alkyl levulinates into GVL via hydrogenation and subsequent dehydration steps [19,31,32]. However, the use of molecular hydrogen typically necessitates a high reaction pressure and expensive noble metals for the catalytic phase, hindering the viability of such approaches. Therefore, the efficient production of GVL from LA without using noble metal catalysts and gaseous hydrogen is still challenging. Recently, the catalytic transfer hydrogenation (CTH) of LA, for instance via a Meerwein-Ponndorf-Verley (MPV) mechanism, using organic hydrogen donors (e.g., formic acid, 2-propanol) has been extensively studied [33-37]. In the transfer hydrogenation of LA to GVL, Ni-, Sn- and Zr-based catalysts have attracted much attention because of their non-noble features and high efficiency. These metals incorporated into zeolite, silica or organic polymer frameworks form Lewis acid sites that benefit the CTH reaction [23,38]. Additionally, GVL can also be produced from furfural through a catalytic cascade of reactions consisting of a combination of acid and CTH steps [39-41].

From the point of view of process integration, the fact that GVL can be efficiently produced from levulinic acid and furfural in the same transformation process, results very appealing in terms of biomass conversion economics. In this sense, bifunctional catalysts appear as key players for the development of such an integrated cascade process. Ideally, a one-pot reaction, avoiding the necessity of intermediate separations and purifications, would be possible when using a single catalyst that fulfils the requirements of each reaction step. While some of the steps require Brønsted acid sites, originating, for instance, from the inclusion of $\mathrm{Al}$ in zeolite structures, the MPV reduction of carbonyl groups is essentially promoted by Lewis acid sites, like those coming from the presence of Sn, Hf, Ti and $\mathrm{Zr}$ species [12,41-43]. The combination of both acid functionalities within the same heterogeneous catalyst might enable the step-by-step conversion of products to increase the selective one-pot one-catalyst production of GVL as the end product [39].

In this context, the one-step production of biomass-derived platform molecules was investigated using Sn-Al- and $\mathrm{Zr}-\mathrm{Al}$-containing beta zeolites [44-46]. Several works have dealt with the improvement of the physicochemical properties of bifunctional catalysts, or with the optimization of the reaction conditions [47-49]. In this field, our group has recently reported a family of $\mathrm{Zr}-\mathrm{Al}$-beta zeolites, synthesized via the post-synthetic modification of a dealuminated commercial beta zeolite. Such materials have been shown to be adequate catalysts for the direct and efficient production of GVL in isopropanol, not only from furfural and levulinic acid [22,50], but also from the corresponding parent monosaccharides, xylose [51,52] and glucose [53]. By tuning both the catalyst synthesis and the reaction conditions, these materials can be adapted to maximize the performance of the catalyst in terms of GVL yield and the efficient use of the respective biomass-derived substrate.

Considering the growing interest in LA conversion, developing more efficient and scalable processes is still necessary. Moreover, providing the proper heterogeneous catalyst into packed bed continuous flow reactors would allow treating the biomass-derived platform molecules in a continuous 
manner, thus enhancing the productivity and reducing production costs, as well as introducing the possibility of testing the catalyst for stability in long periods of time on stream. Despite all these advantages, few investigations dealing with the continuous production of GVL through MPV transfer hydrogenation in packed bed reactors have been published. While the transformation of methyl levulinate into GVL under continuous flow has been recently reported, by using Zr-modified Metal-Organic-Framework (MOF) (UiO-66) [54] and Zr-based mesoporous materials [55], to the best of our knowledge, the direct transformation of levulinic acid and/or furfural has not been tackled yet.

Thus, in this work we take a step further and demonstrate the application of $\mathrm{Zr}$-Al-Beta zeolites for the one-pot catalytic transformation of levulinic acid into GVL in a continuous fixed-bed reactor. The different aspects related with the physicochemical properties of the catalyst and the influence of these in the cascade transformation under continuous-flow conditions are evaluated. In addition, different parameters such as flow, temperature and concentration are analyzed. We also report the exceptional stability of the catalyst in the long term on stream assays in a continuously packed bed reactor.

\section{Results and Discussion}

GVL production in a lignocellulosic biorefinery producing both furfural (FAL) and levulinic acid (LA) is of great interest. Once the one-pot transformation has been successfully demonstrated in a batch-reactor configuration [22], the implementation of FAL and LA transformation in a continuous packed bed reactor holds an interest in order to scale the process up. The presented bifunctional $\mathrm{Zr}$-Al-Beta catalyst harbors the key to such an efficient process.

\subsection{Zr-Al-Beta Catalyst}

Table 1 summarizes the most important physicochemical properties for the parent beta zeolite and the $\mathrm{Zr}-\mathrm{Al}$-Beta zeolite prepared under the optimal synthesis conditions previously reported [22]. The removal of the $\mathrm{Al}$ species from the BEA framework of the commercial beta zeolite, combined with the subsequent incorporation of the $\mathrm{Zr}$ species, decreases the overall acidity of the material. Additionally, replacing the aluminum species by zirconium species reduces the Brønsted/Lewis (B/L) acid sites ratio (Figure S1). Remarkably, despite the Lewis acidity being predominant in Zr-Al-Beta, the modified zeolite still contains a certain amount of Brønsted acid sites, necessary to catalyze the acid steps involved in the cascade of reactions from FAL or LA to give GVL.

Table 1. Physicochemical properties of the parent beta and the modified $\mathrm{Zr}-\mathrm{Al}$-Beta zeolite.

\begin{tabular}{|c|c|c|c|c|c|c|c|c|c|}
\hline \multirow[b]{2}{*}{ Catalyst } & \multicolumn{5}{|c|}{ Composition $^{a}$} & \multirow{2}{*}{$\begin{array}{c}\text { BET }{ }^{b} \\
\left(\mathrm{~m}^{2} \mathrm{~g}^{-1}\right)\end{array}$} & \multirow{2}{*}{$\begin{array}{c}V_{p}^{c} \\
\left(\mathrm{~cm}^{3} \mathrm{~g}^{-1}\right)\end{array}$} & \multicolumn{2}{|c|}{ Acidity } \\
\hline & $\% \mathrm{Al}$ & $\% \mathbf{Z r}$ & Si/Al & $\mathrm{Si} / \mathrm{Zr}$ & $\mathrm{Al} / \mathrm{Zr}$ & & & $\begin{array}{c}\left(\mathrm{mmol} \mathrm{H} \mathrm{H}^{+}\right. \\
\left.\mathrm{g}^{-1}\right)^{\mathrm{d}}\end{array}$ & $\begin{array}{c}\text { B/L } \\
\text { Ratio }^{\text {e }}\end{array}$ \\
\hline Beta (parent) & 2.0 & 0.0 & 22 & - & - & 623 & 0.36 & 0.41 & 0.56 \\
\hline $\mathrm{Zr}-\mathrm{Al}$-Beta & 0.3 & 4.5 & 156 & 32 & 0.20 & 685 & 0.38 & 0.29 & 0.05 \\
\hline
\end{tabular}

a $\% \mathrm{Al}, \% \mathrm{Zr}(w t / w t) ; \mathrm{Si} / \mathrm{Al}, \mathrm{Si} / \mathrm{Zr}, \mathrm{Al} / \mathrm{Zr}$ (atomic ratios) as measured by ICP-OES. ${ }^{\mathrm{b}}$ Surface area obtained by the BET method. ${ }^{c}$ Total pore volume at $\mathrm{P} / \mathrm{P}_{0}=0.98 .{ }^{\mathrm{d}}$ Acid sites loading as determined by $\mathrm{NH}_{3}-\mathrm{TPD}$. ${ }^{\mathrm{e}}$ Brønsted/Lewis ratio as determined by pyridine-FTIR.

\subsection{Fixed-Bed Transformation of Furfural into $\gamma$-Valerolactone}

As it has been described in the literature, the FAL conversion into GVL in isopropanol involves multiple sequential reaction steps and can be advantageously carried out over a bifunctional catalyst in a one-pot one-catalyst strategy $[44,50]$. The cascade process starts with the transfer hydrogenation of FAL into furfuryl alcohol (FOL) and its subsequent etherification into isopropyl furfuryl ether (FE), which readily evolves by hydration into levulinic acid (LA). Through acid-catalyzed dehydration, LA can further evolve to give $\alpha / \beta$-angelica lactones (ANG). However, the main transformation pathway for LA in isopropanol media in the presence of an acid catalyst is the formation of the corresponding ester, the isopropyl levulinate (iLEV). Finally, the transfer hydrogenation of these compounds, LA and/or 
iLEV, followed by the acid-catalyzed lactonization of the resultant 4-hydroxypentanoic acid/ester, produces GVL (Scheme 1).

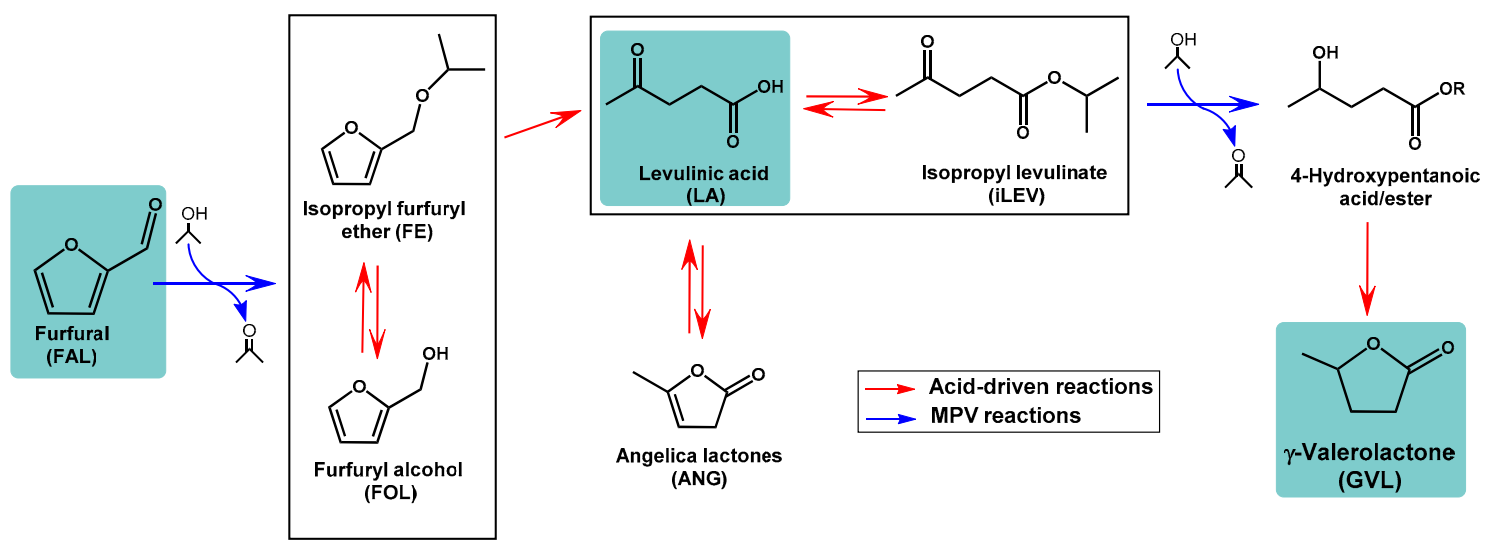

Scheme 1. Proposed cascade transformation of furfural and/or levulinic acid into GVL through the alternating acid-catalyzed and Meerwein-Ponndorf-Verley (MPV) reaction steps in isopropanol over a bifunctional Brønsted/Lewis catalyst.

For the continuous-flow packed bed assay, previously optimized reaction conditions were used, i.e., $6 \mathrm{~g} \cdot \mathrm{L}^{-1}$ FAL concentration in isopropanol as the feed inlet, and at a mild temperature $\left(150{ }^{\circ} \mathrm{C}\right)$. Likewise, a moderate volume flow rate was established to assure a good contact between the reactant and the catalyst (contact time $5 \mathrm{~min} \cdot \mathrm{g} \cdot \mathrm{mL}^{-1}$ ). Figure 1 shows the results of the continuous catalytic run performed to evaluate the conversion of FAL as well as the products distribution for a time stream of up to $6 \mathrm{~h}$. Furfural conversion displays values over $90 \mathrm{~mol} \%$ and close to the total conversion during the whole experiment, following the same trend observed when running the experiment in an equivalent batch-mode operation [50]. Once the steady state operation is achieved $\left(t_{0}\right.$, time on stream $\left.=0\right)$, the yields towards the different products fairly reflect the results obtained in discontinuous operation, but in a much faster and efficient way: $40 \mathrm{~mol} \%$ yield to GVL with a contact time of $5 \mathrm{~min} \cdot \mathrm{g} \cdot \mathrm{mL}^{-1}$ versus the reaction times of several hours in batch mode. However, as the time of operation increases, there is a clear change in the yields towards the different compounds, significantly increasing the yield to intermediate compounds (especially, furfuryl alcohol and ether, FOL + FE) at the expense of drastically reducing the production of GVL. This is a clear indication of a fast catalyst deactivation phenomenon, most likely due to the deposition of carbonaceous compounds, such as humins, whose formation is usually linked to the presence of strong acid sites and which has been previously reported for the furfural and xylose conversion in a batch reactor [43,52].

The formed organic deposits may attach to the $\mathrm{Al}$ sites (Brønsted sites), hindering the acid steps, and subsequently blocking the whole cascade and preventing the eventual formation of GVL. On the other hand, $\mathrm{Zr}$ sites seem to continue to be active as the transfer hydrogenation of FAL to give FOL is still happening. This observed trend is consistent with a much more numerous population of $\mathrm{Zr}$ sites than $\mathrm{Al}$ sites $(\mathrm{Al} / \mathrm{Zr}=0.20$, Table 1$)$, thus the fouling of $\mathrm{Al}$ sites is the most probable cause of the inactivation of the catalyst. It must be noted that such a deactivation is reversible by thermal treatment in the air $\left(5 \mathrm{~h}\right.$ at $\left.550{ }^{\circ} \mathrm{C}\right)$, as it was shown in previous works [22]. 


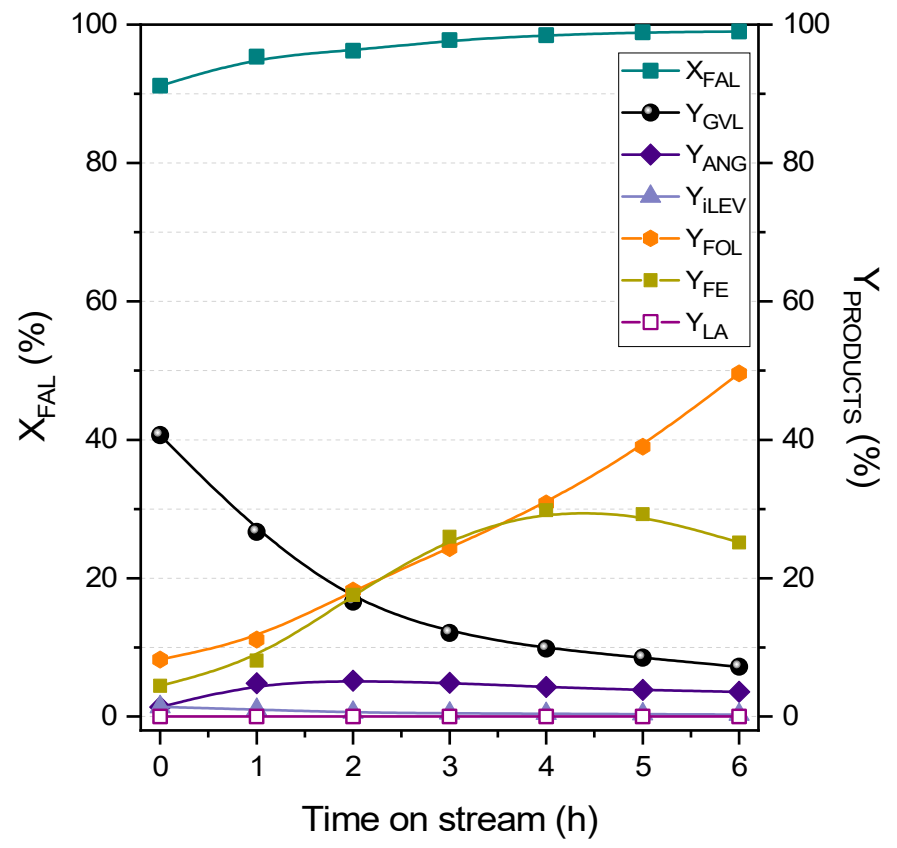

Figure 1. Conversion and product yield profiles in the transformation of furfural versus the time on the stream obtained in the packed-bed reactor charged with the bifunctional $\mathrm{Zr}-\mathrm{Al}$-Beta catalyst operating under steady-state conditions. Reaction conditions: temperature $=150{ }^{\circ} \mathrm{C}$; catalyst weight $=0.25 \mathrm{~g}$; FAL concentration $=6 \mathrm{~g} \cdot \mathrm{L}^{-1} ;$ feed flow rate $=0.05 \mathrm{~mL} \cdot \mathrm{min}^{-1} ;$ contact time $=5 \mathrm{~min} \cdot \mathrm{g} \cdot \mathrm{mL}^{-1}$.

\subsection{Fixed-Bed Transformation of Levulinic Acid into $\gamma$-Valerolactone}

LA conversion into GVL avoids some of the steps in the cascade of reactions as compared to FAL transformation (Scheme 1). Levulinic acid can be esterified into the isopropyl levulinate (iLEV) and both can be reduced to 4-hydroxypentanoic acid or ester, and further converted into GVL via acid-catalyzed lactonization. In this way, the bifunctional Zr-Al-Beta zeolite was then catalytically tested in the same packed-bed reactor, but the substrate was changed into levulinic acid (solution of $6 \mathrm{~g} \cdot \mathrm{L}^{-1}$ in isopropanol), using the same mild temperature $\left(150^{\circ} \mathrm{C}\right)$ and flow rate $\left(0.05 \mathrm{~mL} \cdot \mathrm{min}^{-1}\right)$ (Figure 2). It should be noted that the catalyst used for this next experiment was the same as that of the previous study for furfural transformation after the thermal reactivation $\left(5 \mathrm{~h}\right.$ at $\left.550{ }^{\circ} \mathrm{C}\right)$.

The results included in Figure 2A evidence of the high activity and selectivity to GVL achieved in continuous flow, keeping sustained values of the GVL yield over $60 \%$ for more than $220 \mathrm{~h}$ of non-stop time on stream (tos), with a selectivity ca. $90 \%$. Considering the contact time fixed for this experiment, $5 \mathrm{~min} \cdot \mathrm{g} \cdot \mathrm{mL}^{-1}$, it is clear that the reaction rates are enhanced compared to those of batch configuration [22]. This fact can be attributed to a more intimate contact between the reactants and the catalyst in the packed bed. Noticeably, a small continuous drop in activity can be observed during the first 5 days of operation, from a maximum of $70 \%$ GVL yield and $76 \%$ LA conversion to more stable values of $60-63 \%$ GVL yield from the fifth day (tos $>120 \mathrm{~h}$ ). As in the case of furfural, this decay might be attributed to the formation of organic deposits, but they must be small and with limited influence. In order to evaluate the extent of the deactivation, a new in situ thermal treatment was applied to the $\mathrm{Zr}-\mathrm{Al}$-Beta. Figure 2B displays the results obtained after the catalyst bed regeneration, confirming a very similar performance: a GVL yield initially over $70 \%$ and the progressive slow decay of activity during the 5 days, leading to a stable behavior slightly over $60 \%$ GVL yield for the rest of the experiment (up to $250 \mathrm{~h}$ ). This result confirms that the slow activity decrease is reversible through calcination, so it may be caused by the formation of scarce organic deposits over the catalyst surface. Their formation is usually linked to the presence of strong acid sites and has been previously reported for furfural, xylose and levulinic acid conversion in a batch reactor [22,43,52]. However, it must be 
highlighted that the loss of activity has a limit, from which the fixed bed reactor works in an extremely stable fashion.
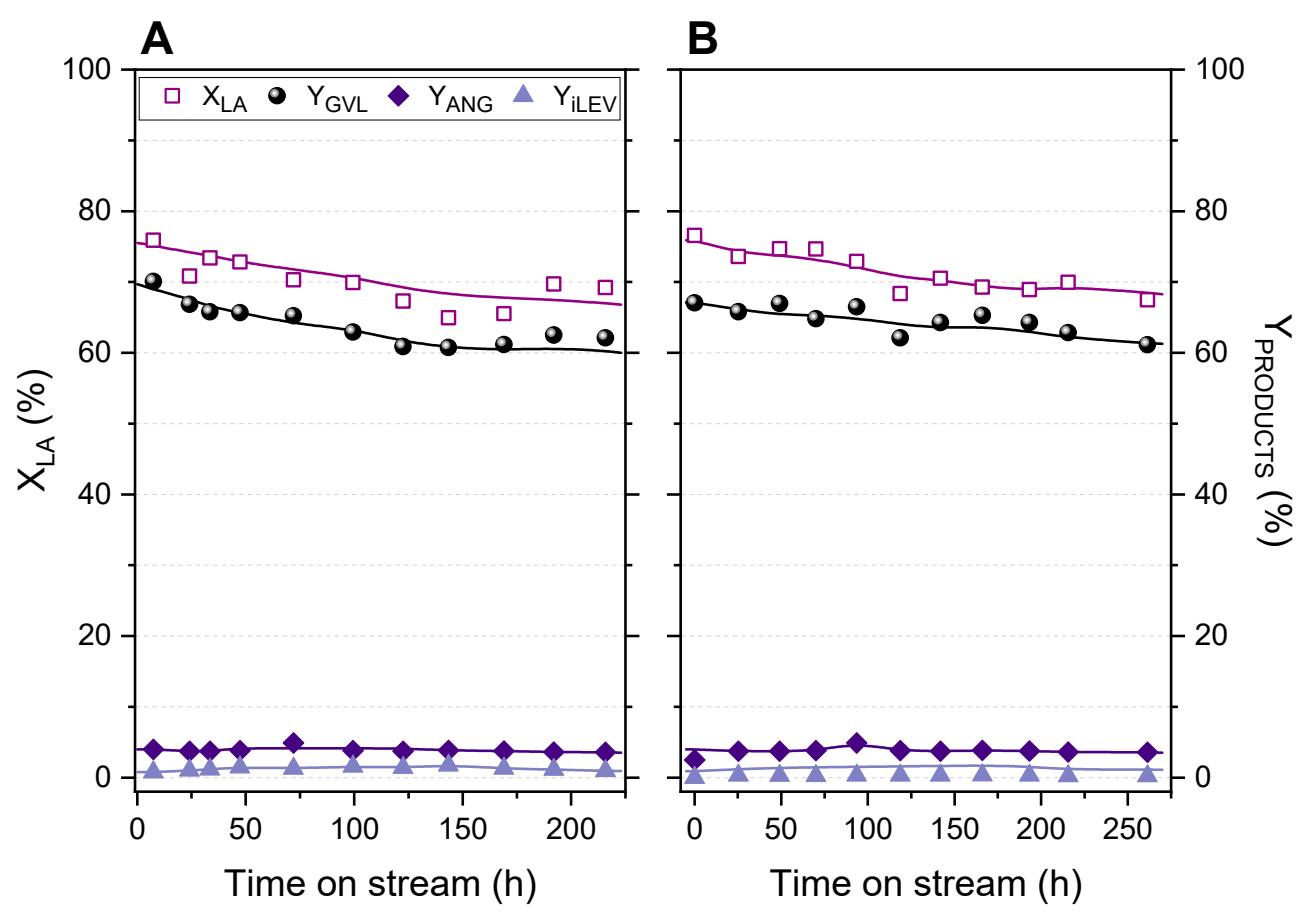

Figure 2. (A) Conversion and product yield profiles in the transformation of LA versus the time on the stream obtained in the packed-bed reactor charged with the bifunctional $\mathrm{Zr}-\mathrm{Al}$-Beta catalyst operating under steady-state conditions. Reaction conditions: temperature $=150{ }^{\circ} \mathrm{C}$; catalyst weight $=0.25 \mathrm{~g}$; LA concentration $=6 \mathrm{~g} \cdot \mathrm{L}^{-1}$; feed flow rate $=0.05 \mathrm{~mL} \cdot \mathrm{min}^{-1}$; contact time $=5 \mathrm{~min} \cdot \mathrm{g} \cdot \mathrm{mL}^{-1}$. (B) LA transformation under the same reaction conditions after the in situ calcination in the air flow $(5 \mathrm{~h}$ at $550{ }^{\circ} \mathrm{C}$ ).

Aside from $\gamma$-valerolactone, two additional minor products were identified, namely isopropyl levulinate and $\alpha / \beta$-angelica lactone (Figure 2). On the one hand, the isopropyl ester comes from the esterification in the alcohol media of the substrate, which can undergo the same carbonyl group reduction as levulinic acid itself (MPV transfer hydrogenation). As this product is a reaction intermediate, which evolves fast into the following product in the cascade of reactions, its yield remains negligible for the whole accumulated sequence of about $500 \mathrm{~h}$ of operation (considering together the experiments before and after catalyst regeneration). On the other hand, $\alpha / \beta$-angelica lactones can be obtained via LA dehydration in the presence of strong acid sites, such as the aluminium Brønsted acid sites present within the bifunctional zeolite $[56,57]$. However, under the reaction conditions, these lactones also remain in low yield, around $5 \%$, throughout both experiments. Thus, it must be considered that the LA conversion is in a continuous reactor with a packed bed of the bifunctional $\mathrm{Zr}-\mathrm{Al}$ zeolite predominantly follows the expected MPV reduction to give GVL, but the acid dehydration to give ANG also takes place to a minor extent.

Subsequently, after a new thermal regeneration of the catalyst, the next experiment was initiated raising the bed temperature to $170{ }^{\circ} \mathrm{C}$, and keeping an uninterrupted stationary state for a total of $460 \mathrm{~h}$ with the same LA concentration and contact time. Figure 3 shows the results, also including for comparison purposes an equivalent catalytic run carried out in batch mode (under previously optimized reaction conditions [22]). Firstly, Figure $3 \mathrm{~A}$ reveals that with a temperature rise of just $20^{\circ} \mathrm{C}$, from $150{ }^{\circ} \mathrm{C}$ to $170{ }^{\circ} \mathrm{C}$, the GVL yield sharply increases up to $\sim 90 \%$ with a LA conversion of $\sim 95 \%$. Moreover, what is very remarkable is that this result remains stable for at least 19 consecutive days of experiment (without any regeneration or washing treatment of the catalyst), the time for which the 
experiment was stopped. Figure 3B includes the kinetic curves obtained in the batch study. As shown, the maximum GVL (over 90\%) needs approximately two hours to be reached, accompanied by an almost total conversion of LA. Both experiments, continuous and batch, seem to reach similar final results in terms of the yield to GVL. This opens up new opportunities for the industrial production of GVL via the transfer hydrogenation of levulinic acid.
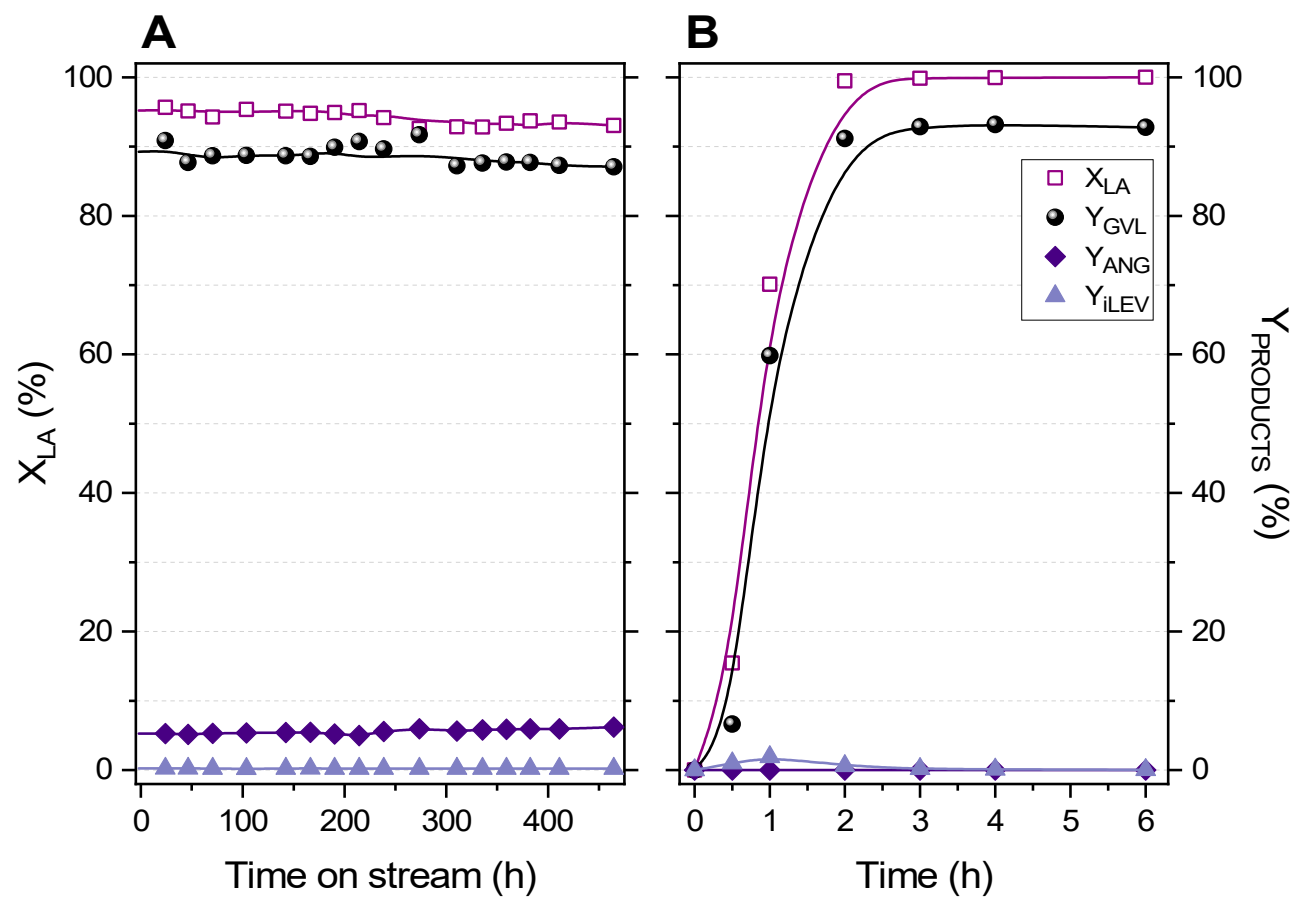

Figure 3. (A) Conversion and product yield profiles in the transformation of LA versus the time on the stream obtained in the packed-bed reactor charged with the bifunctional $\mathrm{Zr}$-Al-Beta catalyst operating under steady-state conditions. Reaction conditions: temperature $=170{ }^{\circ} \mathrm{C}$; catalyst weight $=0.25 \mathrm{~g}$; LA concentration $=6 \mathrm{~g} \cdot \mathrm{L}^{-1}$; feed flow rate $=0.05 \mathrm{~mL} \cdot \mathrm{min}^{-1}$; contact time $=5 \mathrm{~min} \cdot \mathrm{g} \cdot \mathrm{mL}^{-1}$. (B) Product yields in the transformation of LA in batch mode operation. Reaction conditions: temperature $=170{ }^{\circ} \mathrm{C}$; catalyst loading $=12.5 \mathrm{~g} \cdot \mathrm{L}^{-1} ; \mathrm{LA}$ concentration $=18 \mathrm{~g} \cdot \mathrm{L}^{-1}$.

\subsection{Analysis of Reaction Variables: LA Concentration, Flow Rate, Temperature}

In order to increase the productivity of GVL, a more concentrated solution of levulinic acid was assessed. Under batch-mode operation, a concentration as high as $300 \mathrm{~g} \cdot \mathrm{L}^{-1}$ was successfully processed, though reaching lower figures of conversion and yield [22]. It must be noted that the interest in higher concentrations would not only respond to a higher productivity of GVL, but also to a reduction of the dimensions and costs of the down-stream isopropanol separation and recirculation units. Here, for the fixed bed experiment, the concentration of the inlet solution was first increased 10-fold, from 6.0 to $60 \mathrm{~g} \cdot \mathrm{L}^{-1}$. Additionally, to assure an effective contact time for treating such an increase in substrate flow, the inlet flow rate was reduced to $0.025 \mathrm{~mL} \cdot \mathrm{min}^{-1}$, in the lower limit of the used HPLC pump, assuring a proper control of the stationary flow.

Figure 4 displays the results obtained in this new experiment. As shown in Figure 4A, despite the 10 -fold increase in the concentration of the substrate, the catalytic results stay in significant numbers, with stable GVL yields in the range of $70-75 \%$ and LA conversions of about $85 \%$. This indicates a slight decay in the selectivity towards GVL, as compared to the previous experiment in more diluted conditions. Indeed, the yields to the side-products become more relevant: ANG yield around 8\%, iLEV yield around $4 \%$. It appears that, although the temperature has not changed, the increase in LA concentration favors the side formation of $\alpha / \beta$-angelica lactones through the dehydration catalyzed by Al Brønsted acid sites [56,57]. Noticeably, considering all the products together, the mass 
balance was almost closed, meaning that only small amounts of humins, if any, are being produced. Additionally, the catalytic behavior again remains stable for long times on the stream (up to over 10 uninterrupted days).
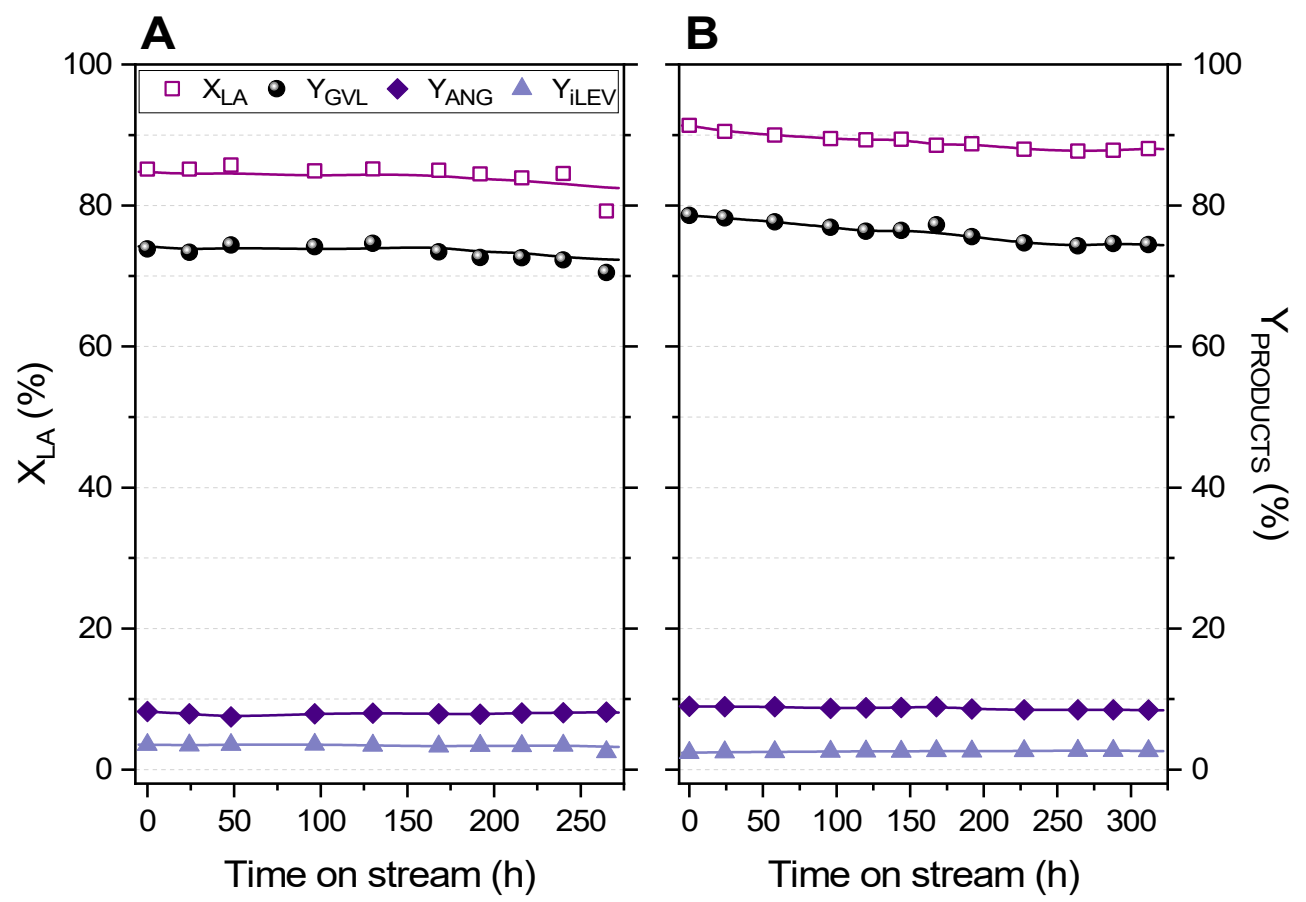

Figure 4. (A) Conversion and product yield profiles in the transformation of LA versus the time on the stream obtained in the packed-bed reactor charged with the bifunctional $\mathrm{Zr}-\mathrm{Al}$-Beta catalyst operating under steady-state conditions. Reaction conditions: temperature $=170{ }^{\circ} \mathrm{C}$; catalyst weight $=0.25 \mathrm{~g}$; LA concentration $=60 \mathrm{~g} \cdot \mathrm{L}^{-1}$; feed flow rate $=0.025 \mathrm{~mL} \cdot \mathrm{min}^{-1}$; contact time $=10 \mathrm{~min} \cdot \mathrm{g} \cdot \mathrm{mL}^{-1}$. (B) LA transformation under the same reaction conditions after the in situ calcination in the air $\left(5 \mathrm{~h}\right.$ at $\left.550{ }^{\circ} \mathrm{C}\right)$.

After $270 \mathrm{~h}$ of continuous operation, and in view of the otherwise small decay of the catalytic activity, the bed of $\mathrm{Zr}-\mathrm{Al}$-Beta was again subjected to an in situ calcination, in order to reactivate the material. Figure $4 \mathrm{~B}$ includes the results obtained after a such reactivation of the catalyst, showing a total recovery and even a slight improvement of the catalytic performance in terms of the yield to GVL and conversion of LA. This set-up was continued for $>300 \mathrm{~h}$ keeping similar results in a sustainable way. Only a very slow descent in the GVL yield, from $79 \%$ to $75 \%$, was observed in that period of time (>12 days).

In view of the promising results after increasing the substrate concentration, a step forward was taken. Figure 5A shows the results using an initial LA concentration of $220 \mathrm{~g} \cdot \mathrm{L}^{-1}$. The experiment was carried out under the same reaction conditions previously used $-170{ }^{\circ} \mathrm{C}$, flow rate of $0.025 \mathrm{~mL} \cdot \mathrm{min}^{-1}$, and contact time of $10 \mathrm{~min} \cdot \mathrm{g} \cdot \mathrm{mL}^{-1}$ — with the exception of the mentioned increase in the substrate concentration. As shown, there is a notable fall in the values of conversion and yield to GLV, as it would be expected since the catalytic bed mass and dimensions remain unaltered. Thus, comparing the previous concentration of $60 \mathrm{~g} \cdot \mathrm{L}^{-1}$, the LA conversion decreases from $\sim 85-90 \%$ to $\sim 67 \%$. Furthermore, the product distribution is different; the GVL yield decreases to $\sim 42 \%$, and a clear increase in the yield to the levulinate (iLEV), up to $20 \%$, is observed. We hypothesize that this behavior is attributed to a saturation of the active sites in a highly concentrated medium, leading to an incomplete transformation into GVL (one third of the fed levulinic acid remains unreacted). However, though the percent of GVL yield was reduced, the actual production of GLV in absolute terms was enhanced, as discussed below (Table 2). 

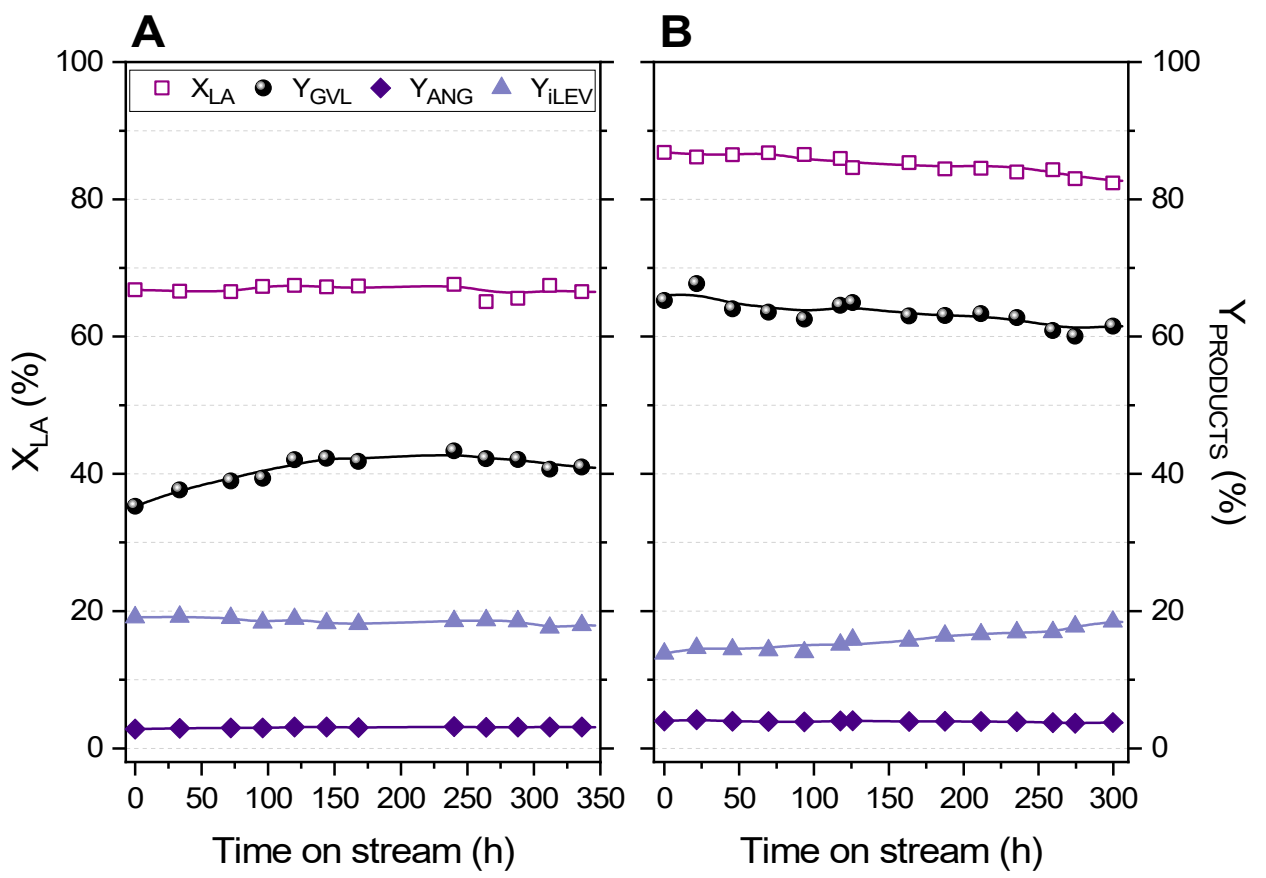

Figure 5. (A) Conversion and product yield profiles in the transformation of LA versus the time on the stream obtained in the packed-bed reactor charged with the bifunctional $\mathrm{Zr}-\mathrm{Al}$-Beta catalyst operating under steady-state conditions. Reaction conditions: temperature $=170{ }^{\circ} \mathrm{C}$; catalyst weight $=0.25 \mathrm{~g}$; LA concentration $=220 \mathrm{~g} \cdot \mathrm{L}^{-1}$; feed flow rate $=0.025 \mathrm{~mL} \cdot \mathrm{min}^{-1}$; contact time $=10 \mathrm{~min} \cdot \mathrm{g} \cdot \mathrm{mL}^{-1}$. (B) LA transformation under the same reaction conditions increasing the temperature to $190{ }^{\circ} \mathrm{C}$ after the in situ calcination in the air $\left(5 \mathrm{~h}\right.$ at $\left.550^{\circ} \mathrm{C}\right)$.

Table 2. Productivity of GVL in the fixed-bed transfer hydrogenation of LA using Zr-Al-Beta as catalyst ${ }^{\mathrm{a}}$.

\begin{tabular}{ccccccc}
\hline $\begin{array}{c}\text { Experiment } \\
\#\end{array}$ & $\begin{array}{c}\text { Temperature } \\
\left({ }^{\circ} \mathbf{C}\right)\end{array}$ & $\begin{array}{c}\text { Flow Rate } \\
(\mathbf{m L} / \mathbf{m i n})\end{array}$ & $\begin{array}{c}\text { LA Concentr. } \\
(\mathbf{g} / \mathbf{L})\end{array}$ & $\mathbf{Y}_{\mathbf{G V L}}{ }^{\mathbf{b}}(\mathbf{\%})$ & $\mathbf{S}_{\mathrm{GVL}}{ }^{\mathbf{c}}(\mathbf{\%})$ & $\begin{array}{c}\text { Productivity } \\
\left(\mathbf{g}_{\mathrm{GVL}} / \mathbf{h} \cdot \mathbf{g}_{\text {cat }}\right)\end{array}$ \\
\hline 1 & 150 & 0.050 & 6 & 60 & 88 & 2.2 \\
2 & 170 & 0.050 & 6 & 90 & 95 & 3.4 \\
3 & 170 & 0.025 & 60 & 75 & 88 & 14.0 \\
4 & 170 & 0.025 & 220 & 42 & 62 & 28.7 \\
5 & 190 & 0.025 & 220 & 65 & 76 & 44.4 \\
\hline
\end{tabular}

${ }^{\mathrm{a}}$ Amount of packed catalyst $=0.25 \mathrm{~g} .{ }^{\mathrm{b}}$ Average yield to GVL. ${ }^{\mathrm{c}}$ Average selectivity to GVL.

In order to further explore the performance of the $\mathrm{Zr}$-Al-beta zeolite as the catalyst, an additional experiment was performed raising the reaction temperature to $190{ }^{\circ} \mathrm{C}$. Although no evidence of catalyst deactivation was observed in the previous experiment after $350 \mathrm{~h}$ of uninterrupted operation (Figure 5A), a new in situ activation of the catalysts was applied prior to establishing the new steady state. Figure 5B depicts the conversion and yield profiles for such a highly LA-concentrated experiment at the increased temperature. As shown, a significant increase in LA conversion and GVL yield was evidenced (up to $85 \%$ conversion, and $65 \%$ GVL yield). However, the selectivity to GVL remains low because of the increased presence of iLEV in the product stream ( 15\%). Despite the higher temperature, we hypothesized that a saturation effect of the catalytic sites must be taking place under such a high concentration of LA $\left(220 \mathrm{~g} \cdot \mathrm{L}^{-1}\right)$ in the feed flow. Interestingly, a slow but sustained decay in the activity of the catalyst can be inferred from the trend in LA conversion and GVL yield with the time on stream. We attribute this to the enhanced formation of non-desired heavy by-products (humins), formed particularly over Brønsted acid sites (in this case, the remaining Al sites in the Al-Zr-Beta zeolite). Such sites are few in comparison with $\mathrm{Zr}$ sites, but they play an important role in the acid-catalyzed steps of the reaction mechanism (Scheme 1, arrows in red). In turn, this deactivation phenomenon seems 
to favor the presence of iLEV in the product, as an intermediate in the transformation. The elevated temperature enhances the deactivation of the catalyst, so it would not be interesting to use higher temperatures. Most likely, under these conditions, an increase in contact time would be useful to reduce the selectivity to undesired products such as iLEV, although this would come at the expense of reducing the productivity of the catalyst.

To analyze the previous results from a more industrial point of view, that is, considering the production capacity, Table 2 presents the specific productivities of GVL corresponding to each experimental set-up in terms of the grams of GVL produced hourly per gram of catalyst. As shown in the table, in the packed-bed configuration, productivities are high, reaching values up to $44.4 \mathrm{~g}_{\mathrm{GVL}} \cdot \mathrm{h}^{-1} \cdot \mathrm{g}_{\mathrm{cat}}{ }^{-1}$ under the more stringent conditions (exp\# 5, Table 2). However, if a more selective process is desired, the conditions of exp\# 2 would be preferred, as they provide the higher yield and selectivity to GVL, though with a much more limited productivity.

In conclusion, the $\mathrm{Zr}$-Al-beta catalyst worked in a very successful way for extraordinarily long times on stream in the transformation of levulinic acid into $\gamma$-valerolactone in an isopropanol medium. Additionally, it is worthy to highlight that the catalyst in the packed bed was not changed during the whole experimentation, accumulating a total time of service of aprox. $2500 \mathrm{~h}$ (over 100 days). It has just been reactivated by thermal treatment in a continuous air flow $\left(5 \mathrm{~h}, 550^{\circ} \mathrm{C}\right)$ when necessary, completely recovering its full activity.

\section{Materials and Methods}

\subsection{Catalyst Synthesis}

The synthesis of the zirconium-modified beta zeolite (Zr-Al-Beta) was performed as described elsewhere [50,52]. Briefly, a commercially available beta zeolite (Zeolyst International, $\mathrm{Si} / \mathrm{Al}=22$ ) was taken as the parent material. It was subjected to partial dealumination by nitric acid $\left(6.5 \mathrm{M} \mathrm{HNO}_{3}\right.$, $\left.1 \mathrm{~h}, 25^{\circ} \mathrm{C}, 20 \mathrm{~mL} \cdot \mathrm{g}^{-1}\right)\left(60 \%\right.$ aq. $\mathrm{HNO}_{3}$, Scharlau). The dealuminated zeolite was then rinsed with milli-Q water several times, until it the reached neutral $\mathrm{pH}$. The resulting material was recovered by centrifugation and dried overnight at $100^{\circ} \mathrm{C}$. Zirconium functionalization was accomplished by suspending the partially dealuminated zeolite in an aq. solution of zirconium (IV) nitrate (Chemical Point). The water excess was removed under vacuum, and the resultant solid was dried overnight and calcined in air, first at $200^{\circ} \mathrm{C}\left(6 \mathrm{~h}, 3^{\circ} \mathrm{C} \cdot \mathrm{min}^{-1}\right)$ and then at $550{ }^{\circ} \mathrm{C}\left(6 \mathrm{~h}, 3^{\circ} \mathrm{C} \cdot \mathrm{min}^{-1}\right)$.

\subsection{Catalyst Characterization}

The $\mathrm{Zr}$ and $\mathrm{Al}$ content was determined by means of Inductively Coupled Plasma Optical Emisión Spectrometry (ICP-OES) in a Varian Vista AX spectrophotometer. Argon adsorption-desorption isotherms, recorded at $87 \mathrm{~K}$ using an AutoSorb AS1 equipment (Quantachrome Instruments, Boynton Beach, FL, USA), were used for the determination of the adsorption properties (Figure S3). Determination of the overall specific external and internal surface area was done according to the Brunauer, Emmett and Teller (BET) method. Mean pore size was estimated using the non-local density functional theory (DFT) calculation method. The total pore volume was considered at a single adsorption point $\left(\mathrm{P} / \mathrm{P}_{0}=0.98\right)$. The $\mathrm{X}$-ray powder diffraction $(\mathrm{XRD})$ patterns were collected on a Philips $X^{\prime}$ pert diffractometer using the $\mathrm{CuK} \alpha$ line in the $2 \theta$ angle range from $5-65^{\circ}$ (step size $0.04^{\circ}$ ) (Figure $\mathrm{S} 4$ ). The total acidity was calculated by the means of temperature-programmed desorption (TPD) of $\mathrm{NH}_{3}$ in a Micromeritics 2910 equipment fitted with a Thermal Conductivity Detector (TCD) (Micromeritics, Norcross, GA, USA). The characterization of the acid sites was conducted using a Diffuse Reflectance Infra-red Fourier Transform (DRIFT) spectroscopy of adsorbed pyridine, using a ThermoScientific Nicolet iS50 FT-IR spectrometer fitted with a Smart Collector accessory, mid/near infrared source and a mercury cadmium telluride (MCT-A) photon detector recording at $77 \mathrm{~K}$ (Thermo Fischer Scientific, Waltham, MA, USA). 


\subsection{Fixed-Bed Catalytic Tests}

Catalytic tests for long times on stream (up to a total accumulated time of $2500 \mathrm{~h}$ ) in an isopropanol solution (Scharlau, 98\%) were carried out in a continuous reaction line equipped with a tubular catalytic reactor and a dosing pump (Figure 6). The catalyst $\left(0.25 \mathrm{~g}\right.$ ) was loaded in $\frac{1}{2}$ " stainless steel tubing and firmly held between silica beds and quartz wool. The reactor tubing was jacketed by an aluminum block that was heated by an electric furnace to keep a constant temperature $\left(150-190^{\circ} \mathrm{C}\right)$. To measure the temperature of the catalyst, a thermocouple was inserted between the aluminum jacket and the reactor, centered at the position of the catalyst bed. The pressure was maintained by a backpressure regulator set at 50 bar, using a flow of $\mathrm{N}_{2}$ downstream from the catalyst bed. Once at 50 bar and at the reaction temperature, a solution with the reactants was pumped by a Gilson HPLC pump at a given flow rate ( $t_{0}$ of the experiment). The feed consisted of a solution of the corresponding substrate in isopropanol (concentration ranging from 6 to $220 \mathrm{~g} \cdot \mathrm{L}^{-1}$ ), and n-decane (Acros Organics, Geel, Belgium, $>99 \%)$, added as an internal standard $\left(10 \mathrm{~g} \cdot \mathrm{L}^{-1}\right)$. The substrates used for the experimental runs were furfural (FAL, Sigma Aldrich, St. Louis, MO, USA, 99\%) and levulinic acid (LA, Sigma Aldrich, 98\%). The feed flow rate was kept constant at 0.025 or $0.05 \mathrm{~mL} \cdot \mathrm{min}^{-1}$ leading to a contact time of 10 or $5 \mathrm{~min} \cdot \mathrm{g} \cdot \mathrm{mL}^{-1}$, respectively. The samples were withdrawn from a high-pressure reservoir located upstream from the backpressure regulator that allows the gas/liquid separation and stores the liquids. The liquid samples were accumulated for a given period of time and then collected by draining the reservoir. The actual flow rate coincided with the set flow rate within $\pm 2 \%$. A known amount of the liquid sample was aliquoted and membrane filtered into a vial before analysis. The regeneration of the catalytic bed was performed by the means of an in situ thermal treatment in the tubular catalytic reactor under an air flow at $550{ }^{\circ} \mathrm{C}\left(50 \mathrm{~mL} \cdot \mathrm{min}^{-1}, 5 \mathrm{~h}\right.$, heating ramp $\left.1.8^{\circ} \mathrm{C} \mathrm{min}-1\right)$.

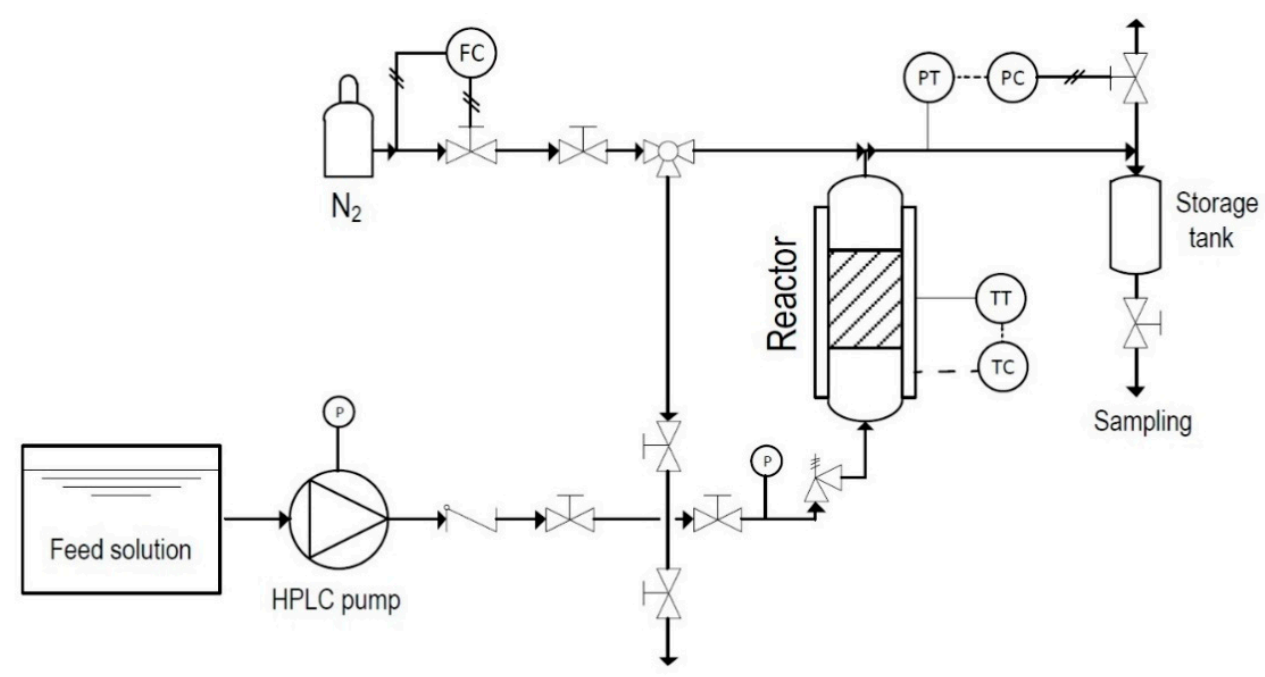

Figure 6. Schematic representation of the flow reactor system.

\subsection{Batch Catalytic Test}

The batch catalytic run was performed in a stirred reactor $(200 \mathrm{~mL})$ made of stainless steel, with a temperature control and a pressure indicator. In order to avoid mass transfer limitations, stirring was fixed at $1000 \mathrm{rpm}$ and the catalyst was used in powder form. The temperature was set, and the heating ramp allowed to reach the desired value within $30 \mathrm{~min}$. The samples were periodically withdrawn and analyzed. $n$-Decane was used as an internal standard $\left(1 \mathrm{~g} \cdot \mathrm{L}^{-1}\right)$. The reaction conditions were $170{ }^{\circ} \mathrm{C}$; catalyst $12.5 \mathrm{~g} \cdot \mathrm{L}^{-1}$; levulinic acid $18 \mathrm{~g} \cdot \mathrm{L}^{-1}$; and a reaction time of up to $6 \mathrm{~h}$. 


\subsection{Products Analysis}

The reaction samples were analyzed by means of gas chromatography (GC), using a Varian 3900 gas chromatograph (Varian, Palo Alto, CA, USA) fitted with an Agilent CP-WAX 52 CB column $(30 \mathrm{~m} \times 0.25 \mathrm{~mm}, \mathrm{DF}=0.25 \mu \mathrm{m}$, Agilent Technologies, Santa Clara, CA, USA) and a Flame Ionization Detector (FID). Product quantification was based on the standard stock solutions of the pure chemicals using an internal standard. The catalytic results are shown either in terms of absolute conversion of the substrate, furfural or levulinic acid $\left(\mathrm{X}_{\mathrm{FAL}}\right.$ or $\left.\mathrm{X}_{\mathrm{LA}}\right)$, or in terms of the yield or selectivity towards the different products (Yi or $\mathrm{S}_{\mathrm{i}}$, respectively). Additionally, the productivity of GVL referred to as the catalyst weight was calculated. The definitions of these parameters applied to the continuous flow reactor are as follows:

$$
\begin{gathered}
\mathrm{X}_{\text {substrate }}=\frac{(\text { Inlet molar flow rate of substrate }- \text { Outlet molar flow rate of susbrate })}{\text { Inlet molar flow rate of substrate }} \times 100 \\
\mathrm{Y}_{\mathrm{i}}=\frac{\text { Outlet molar flow rate of product } \mathrm{i}}{\text { Inlet molar flow rate of substrate }} \times 100 \\
\mathrm{~S}_{\mathrm{i}}=\frac{\text { Outlet molar flow rate of product } \mathrm{i}}{(\text { Inlet molar flow rate of substrate }- \text { Outlet molar flow rate of susbrate })} \times 100 \\
\mathrm{P}_{\mathrm{GVL}}=\frac{\text { Outlet mass flow rate of GVL }}{\text { Grams of catalyst in the catalytic bed }}
\end{gathered}
$$

\section{Conclusions}

The bifunctional Zr-Al-beta catalyst was successfully applied to the production of GVL via the transfer hydrogenation of levulinic acid in a packed-bed reactor configuration, leading to a highly efficient system. Both the high conversions and GVL yields $(>90 \%)$ are shown at moderate temperatures $\left(170^{\circ} \mathrm{C}\right)$. Additionally, the packed-bed system is much more efficient than the equivalent batch operation mode, allowing to achieve the enhanced productivities of GVL (up to $44.4 \mathrm{~g}_{\mathrm{GVL}} \cdot \mathrm{h}^{-1} \cdot \mathrm{g}_{\mathrm{cat}}{ }^{-1}$ ). Importantly, this work evidences the excellent long-term stability of the $\mathrm{Zr}$-Al-Beta catalyst, maintaining a high activity even through the different changes introduced in the reaction conditions (substrate, temperature, concentration). The small activity loss observed under certain circumstances can be easily compensated by a slight increase in the temperature or decrease in the flow rate of the feed. Besides, the in situ calcination in the air flow at $550{ }^{\circ} \mathrm{C}$ fully regenerates the catalyst to its initial state. The obtained results show great potential for applying the $\mathrm{Zr}-\mathrm{Al}$-Beta catalyst in upgrading biomass derivatives to useful biofuel/chemical products, paving the path for green energy production from renewable lignocellulosic biomass.

Supplementary Materials: The following are available online at http://www.mdpi.com/2073-4344/10/6/678/s1, Figure S1: DRIFT signals of adsorbed pyridine on parent (commercial) Beta and Zr-Al-Beta zeolites. Figure S2: NH3-TPD profiles of commercial of commercial H-Beta parent zeolite and $\mathrm{Zr}-\mathrm{Al}-\mathrm{Beta}$ zeolite. Figure S3: Ar adsorption-desorption isotherms of commercial H-Beta zeolite and $\mathrm{Zr}$-Al-Beta (left side). Pore sizes distribution of commercial H-Beta parent zeolite and Zr-Al-Beta (right side). Figure S4: XRD patterns of Zr-Al-Beta, as compared to commercial Beta zeolite and crystalline $\mathrm{ZrO} 2$ (monoclinic phase).

Author Contributions: Conceptualization, G.M., M.P. and C.L.-A.; methodology, C.L.-A.; validation, G.M. and M.P.; formal analysis, G.M. and J.I.; investigation, M.L.G., G.M., M.P., C.L.-A. and P.J.; resources, M.L.G.; writing - original draft preparation, G.M. and C.L.-A.; writing-review and editing, G.M., M.P., J.I., M.L.G. and J.A.M.; visualization, C.L.-A.; supervision, G.M., M.P., J.I., J.A.M. and M.L.G.; project administration, J.A.M., G.M. and J.I.; funding acquisition, J.A.M., G.M. and J.I. All authors have read and agreed to the published version of the manuscript.

Funding: This research was funded by Spanish Ministry of Science, Innovation and Universities, grant number RTI2018-094918-B-C42, Regional Government of Madrid, grant number P2018/EMT-4344 (Biotres); and University Rey Juan Carlos (Young Researchers R\&D Project ref. M2181-Biocavi).

Acknowledgments: We want to acknowledge also the contribution of Yolanda Rodenas for the preparation of the scheme corresponding to the experimental set-up. 
Conflicts of Interest: The authors declare no conflict of interest.

\section{References}

1. Arias, P.L.; Cecilia, J.A.; Gandarias, I.; Iglesias, J.; Granados, M.L.; Mariscal, R.; Morales, G.; Moreno-Tost, R.; Maireles-Torres, P. Oxidation of lignocellulosic platform molecules to value-added chemicals using heterogeneous catalytic technologies. Catal. Sci. Technol. 2020, 10, 2721-2757. [CrossRef]

2. Wang, L.; Wang, H.; Liu, F.; Zheng, A.; Zhang, J.; Sun, Q.; Lewis, J.P.; Zhu, L.; Meng, X.; Xiao, F.-S. Selective Catalytic Production of 5-Hydroxymethylfurfural from Glucose by Adjusting Catalyst Wettability. ChemSusChem 2014, 7, 402-406. [CrossRef]

3. Hu, B.; Wang, K.; Wu, L.; Yu, S.-H.; Antonietti, M.; Titirici, M. Engineering Carbon Materials from the Hydrothermal Carbonization Process of Biomass. Adv. Mater. 2010, 22, 813-828. [CrossRef] [PubMed]

4. Mohan, D.; Pittman, C.U.; Steele, P.H. Pyrolysis of Wood/Biomass for Bio-oil: A Critical Review. Energy Fuels 2006, 20, 848-889. [CrossRef]

5. Alonso, D.M.; Bond, J.Q.; Dumesic, J.A. Catalytic conversion of biomass to biofuels. Green Chem. 2010, 12, 1493. [CrossRef]

6. De Clippel, F.; Dusselier, M.; van Rompaey, R.; Vanelderen, P.; Dijkmans, J.; Makshina, E.V.; Giebeler, L.; Oswald, S.; Baron, G.V.; Denayer, J.F.M.; et al. Fast and Selective Sugar Conversion to Alkyl Lactate and Lactic Acid with Bifunctional Carbon-Silica Catalysts. J. Am. Chem. Soc. 2012, 134, 10089-10101. [CrossRef]

7. Klass, D.L. Biomass for Renewable Energy, Fuels, and Chemicals; Academic Press: Cambridge, MA, USA, 1998; ISBN 9780124109506.

8. Huber, G.W.; Iborra, S.; Corma, A. Synthesis of Transportation Fuels from Biomass: Chemistry, Catalysts, and Engineering. Chem. Rev. 2006, 106, 4044-4098. [CrossRef]

9. Sun, Z.-H.; Fridrich, B.; de Santi, A.; Elangovan, S.; Barta, K. Bright Side of Lignin Depolymerization: Toward New Platform Chemicals. Chem. Rev. 2018, 118, 614-678. [CrossRef]

10. Ennaert, T.; van Aelst, J.; Dijkmans, J.; de Clercq, R.; Schutyser, W.; Dusselier, M.; Verboekend, D.; Sels, B.F. Potential and challenges of zeolite chemistry in the catalytic conversion of biomass. Chem. Soc. Rev. 2016, 45, 584-611. [CrossRef]

11. Zhang, Z.; Song, J.; Han, B. Catalytic Transformation of Lignocellulose into Chemicals and Fuel Products in Ionic Liquids. Chem. Rev. 2016, 117, 6834-6880. [CrossRef]

12. Serrano, D.; Melero, J.A.; Morales, G.; Iglesias, J.; Pizarro, P. Progress in the design of zeolite catalysts for biomass conversion into biofuels and bio-based chemicals. Catal. Rev. 2017, 60, 1-70. [CrossRef]

13. Schutyser, W.; Renders, T.; Bosch, S.V.D.; Koelewijn, S.-F.; Beckham, G.T.; Sels, B.F. Chemicals from lignin: An interplay of lignocellulose fractionation, depolymerisation, and upgrading. Chem. Soc. Rev. 2018, 47, 852-908. [CrossRef] [PubMed]

14. Rinaldi, R.; Jastrzebski, R.; Clough, M.T.; Ralph, J.; Kennema, M.; Bruijnincx, P.C.A.; Weckhuysen, B.M. Paving the Way for Lignin Valorisation: Recent Advances in Bioengineering, Biorefining and Catalysis. Angew. Chem. Int. Ed. 2016, 55, 8164-8215. [CrossRef]

15. Chang, C.; Cen, P.; Ma, X. Levulinic acid production from wheat straw. Bioresour. Technol. 2007, 98, $1448-1453$. [CrossRef] [PubMed]

16. Mukherjee, A.; Dumont, M.-J.; Raghavan, V. Review: Sustainable production of hydroxymethylfurfural and levulinic acid: Challenges and opportunities. Biomass Bioenergy 2015, 72, 143-183. [CrossRef]

17. Fang, Z.; Smith, R.L.; Qi, X. (Eds.) Production of Platform Chemicals from Sustainable Resources; Springer: Singapore, 2017; ISBN 9789811041723.

18. Mascal, M.; Dutta, S.; Wu, L. Preparation of Compounds from Levulinic Acid. U.S. Patent 16/555,710, 12 May 2020.

19. Pileidis, F.D.; Titirici, M. Levulinic Acid Biorefineries: New Challenges for Efficient Utilization of Biomass. ChemSusChem 2016, 9, 562-582. [CrossRef]

20. Werpy, T.; Petersen, G. Top Value-Added Chemicals from Biomass: Volume I-Results of Screening for Potential Candidates from Sugars and Synthesis Gas; Technical Report; Pacific Northwest National Laboratory: Oak Ridge, TN, USA; US Department of Energy: Oak Ridge, TN, USA, 2004. [CrossRef]

21. Hayes, D.J.; Fitzpatrick, S.; Hayes, M.H.B.; Ross, J. The Biofine Process-Production of Levulinic Acid, Furfural, and Formic Acid from Lignocellulosic Feedstocks. In Biorefineries-Industrial Processes and Products; Wiley: Hoboken, NJ, USA, 2008; pp. 139-164. 
22. Morales, G.; Melero, J.A.; Iglesias, J.; Paniagua, M.; López-Aguado, C. From levulinic acid biorefineries to $\gamma$-valerolactone (GVL) using a bi-functional Zr-Al-Beta catalyst. React. Chem. Eng. 2019, 4, 1834-1843. [CrossRef]

23. Osatiashtiani, A.; Lee, A.; Wilson, K.; Lee, K.W.A.F. Recent advances in the production of $\gamma$-valerolactone from biomass-derived feedstocks via heterogeneous catalytic transfer hydrogenation. J. Chem. Technol. Biotechnol. 2017, 92, 1125-1135. [CrossRef]

24. Horváth, I.T.; Mehdi, H.; Fábos, V.; Boda, L.; Mika, L.T. $\gamma$-Valerolactone-A sustainable liquid for energy and carbon-based chemicals. Green Chem. 2008, 10, 238-242. [CrossRef]

25. Yao, K.; Tang, C. Controlled Polymerization of Next-Generation Renewable Monomers and Beyond. Macromolecules 2013, 46, 1689-1712. [CrossRef]

26. Alonso, D.M.; Wettstein, S.G.; Dumesic, J.A. Gamma-valerolactone, a sustainable platform molecule derived from lignocellulosic biomass. Green Chem. 2013, 15, 584. [CrossRef]

27. Bond, J.Q.; Alonso, D.M.; Wang, N.; West, R.M.; Dumesic, J.A. Integrated Catalytic Conversion of -Valerolactone to Liquid Alkenes for Transportation Fuels. Science 2010, 327, 1110-1114. [CrossRef]

28. Yang, Y.; Gao, G.; Zhang, X.; Li, F. Facile Fabrication of Composition-Tuned Ru-Ni Bimetallics in Ordered Mesoporous Carbon for Levulinic Acid Hydrogenation. ACS Catal. 2014, 4, 1419-1425. [CrossRef]

29. Tan, J.J.; Cui, J.; Cui, X.; Deng, T.; Li, X.; Zhu, Y.; Li, Y. Graphene-Modified Ru Nanocatalyst for Low-Temperature Hydrogenation of Carbonyl Groups. ACS Catal. 2015, 5, 7379-7384. [CrossRef]

30. Du, X.; Bi, Q.; Liu, Y.-M.; Cao, Y.; Fan, K. Conversion of Biomass-Derived Levulinate and Formate Esters into $\gamma$-Valerolactone over Supported Gold Catalysts. ChemSusChem 2011, 4, 1838-1843. [CrossRef] [PubMed]

31. Wright, W.R.H.; Palkovits, R. Development of Heterogeneous Catalysts for the Conversion of Levulinic Acid to $\gamma$-Valerolactone. ChemSusChem 2012, 5, 1657-1667. [CrossRef] [PubMed]

32. Gong, Y.; Lin, L.; Yan, Z. Catalytic hydrogenation, and oxidation of biomassderived levulinic acid. BioResources 2011, 6, 686-699.

33. Lázaro, N.; Franco, A.; Ouyang, W.; Balu, A.M.; Romero, A.A.; Luque, R.; Pineda, A. Continuous-Flow Hydrogenation of Methyl Levulinate Promoted by Zr-Based Mesoporous Materials. Catalysts 2019, 9, 142. [CrossRef]

34. Xue, Z.; Liu, Q.; Wang, J.; Mu, T. Valorization of levulinic acid over non-noble metal catalysts: Challenges and opportunities. Green Chem. 2018, 20, 4391-4408. [CrossRef]

35. Lv, J.; Rong, Z.; Wang, Y.; Xiu, J.; Wang, Y.; Qu, J. Highly efficient conversion of biomass-derived levulinic acid into $\gamma$-valerolactone over Ni/MgO catalyst. RSC Adv. 2015, 5, 72037-72045. [CrossRef]

36. Gilkey, M.J.; Xu, B. Heterogeneous Catalytic Transfer Hydrogenation as an Effective Pathway in Biomass Upgrading. ACS Catal. 2016, 6, 1420-1436. [CrossRef]

37. Assary, R.S.; Curtiss, L.A.; Dumesic, J.A. Exploring Meerwein-Ponndorf-Verley Reduction Chemistry for Biomass Catalysis Using a First-Principles Approach. ACS Catal. 2013, 3, 2694-2704. [CrossRef]

38. Xu, S.; Yu, D.; Ye, T.; Tian, P. Catalytic transfer hydrogenation of levulinic acid to? Valerolactone over a bifunctional tin catalyst. RSC Adv. 2017, 7, 1026-1031. [CrossRef]

39. Bui, L.; Luo, H.; Gunther, W.R.; Román-Leshkov, Y. Domino Reaction Catalyzed by Zeolites with Brønsted and Lewis Acid Sites to produce $\gamma$-Valerolactone from Furfural. Angew. Chem. Int. Ed. 2013, 52, 8022-8025. [CrossRef] [PubMed]

40. Iglesias, J.; Melero, J.A.; Morales, G.; Paniagua, M.; Hernández, B.; Osatiashtiani, A.; Lee, A.; Wilson, K. ZrO2-SBA-15 catalysts for the one-pot cascade synthesis of GVL from furfural. Catal. Sci. Technol. 2018, 8, 4485-4493. [CrossRef]

41. Cui, J.; Zhu, Y.; Li, Y.; Tan, J.J.; Deng, T.; Zheng, H. Direct conversion of carbohydrates to? Valerolactone facilitated by a solvent effect. Green Chem. 2015, 17, 3084-3089. [CrossRef]

42. Luo, H.Y.; Lewis, J.D.; Román-Leshkov, Y. Lewis Acid Zeolites for Biomass Conversion: Perspectives and Challenges on Reactivity, Synthesis, and Stability. Annu. Rev. Chem. Biomol. Eng. 2016, 7, 663-692. [CrossRef]

43. López-Aguado, C.; Paniagua, M.; Iglesias, J.; Morales, G.; García-Fierro, J.L.; Melero, J.A. Zr-USY zeolite: Efficient catalyst for the transformation of xylose into bio-products. Catal. Today 2018, 304, 80-88. [CrossRef]

44. Antunes, M.M.; Lima, S.; Neves, P.; Magalhães, A.L.; Fazio, E.; Neri, F.; Pereira, M.T.; Silva, A.D.F.; Silva, C.M.; Rocha, S.M.; et al. Integrated reduction and acid-catalysed conversion of furfural in alcohol medium using Zr,Al-containing ordered micro/mesoporous silicates. Appl. Catal. B Environ. 2016, 182, 485-503. [CrossRef] 
45. Antunes, M.M.; Lima, S.; Neves, P.; Magalhães, A.L.; Fazio, E.; Fernandes, A.; Neri, F.; Silva, C.M.; Rocha, S.M.; Ribeiro, M.F.; et al. One-pot conversion of furfural to useful bio-products in the presence of a Sn,Al-containing zeolite beta catalyst prepared via post-synthesis routes. J. Catal. 2015, 329, 522-537. [CrossRef]

46. Antunes, M.M.; Silva, A.D.F.; Ribeiro, M.F.; Pillinger, M.; Neves, P.; Fernandes, A.; Lima, S.; Valente, A.A. Bulk and composite catalysts combining BEA topology and mesoporosity for the valorisation of furfural. Catal. Sci. Technol. 2016, 6, 7812-7829. [CrossRef]

47. Song, S.; Di, L.; Wu, G.; Dai, W.; Guan, N.; Li, L. Meso-Zr-Al-beta zeolite as a robust catalyst for cascade reactions in biomass valorization. Appl. Catal. B Environ. 2017, 205, 393-403. [CrossRef]

48. Winoto, H.P.; Ahn, B.S.; Jae, J. Production of $\gamma$-valerolactone from furfural by a single-step process using Sn-Al-Beta zeolites: Optimizing the catalyst acid properties and process conditions. J. Ind. Eng. Chem. 2016, 40, 62-71. [CrossRef]

49. Winoto, H.P.; Fikri, Z.A.; Ha, J.-M.; Park, Y.-K.; Lee, H.; Suh, D.J.; Jae, J. Heteropolyacid supported on Zr-Beta zeolite as an active catalyst for one-pot transformation of furfural to $\gamma$-Valerolactone. Appl. Catal. B Environ. 2019, 241, 588-597. [CrossRef]

50. Melero, J.A.; Morales, G.; Iglesias, J.; Paniagua, M.; López-Aguado, C.; López-Aguado, C. Rational Optimization of Reaction Conditions for the One-Pot Transformation of Furfural to $\gamma$-Valerolactone over Zr-Al-Beta Zeolite: Toward the Efficient Utilization of Biomass. Ind. Eng. Chem. Res. 2018, 57, 11592-11599. [CrossRef]

51. Hernández, B.; Paniagua, M.; López-Aguado, C.; Melero, J.A.; Iglesias, J.; Morales, G.; Fierro, J.L.G.; Wolf, P.; Hermans, I. One-pot cascade transformation of xylose into? Valerolactone (GVL) over bifunctional Brønsted-Lewis Zr-Al-beta zeolite. Green Chem. 2016, 18, 5777-5781. [CrossRef]

52. Melero, J.A.; Morales, G.; Iglesias, J.; Paniagua, M.; López-Aguado, C.; Wilson, K.; Osatiashtiani, A. Efficient one-pot production of? Valerolactone from xylose over $\mathrm{Zr}$-Al-Beta zeolite: Rational optimization of catalyst synthesis and reaction conditions. Green Chem. 2017, 19, 5114-5121. [CrossRef]

53. Paniagua, M.; Morales, G.; Melero, J.A.; Iglesias, J.; López-Aguado, C.; Vidal, N.; Mariscal, R.; Granados, M.L.; Martínez-Salazar, I. Understanding the role of $\mathrm{Al} / \mathrm{Zr}$ ratio in $\mathrm{Zr}-\mathrm{Al}$-Beta zeolite: Towards the one-pot production of GVL from glucose. Catal. Today 2020. [CrossRef]

54. Ouyang, W.; Zhao, D.; Wang, Y.; Balu, A.M.; Len, C.; Luque, R. Continuous Flow Conversion of Biomass-Derived Methyl Levulinate into $\gamma$-Valerolactone Using Functional Metal Organic Frameworks. ACS Sustain. Chem. Eng. 2018, 6, 6746-6752. [CrossRef]

55. Molina, M.J.C.; Granados, M.L.; Gervasini, A.; Carniti, P. Exploitment of niobium oxide effective acidity for xylose dehydration to furfural. Catal. Today 2015, 254, 90-98. [CrossRef]

56. Abdelrahman, O.A.; Heyden, A.; Bond, J.Q. Analysis of Kinetics and Reaction Pathways in the Aqueous-Phase Hydrogenation of Levulinic Acid to Form $\gamma$-Valerolactone over Ru/C. ACS Catal. 2014, 4, 1171-1181. [CrossRef]

57. Lima, C.; Monteiro, J.L.; Lima, T.; Paixão, M.W.; Correa, A. Angelica Lactones: From Biomass-Derived Platform Chemicals to Value-Added Products. ChemSusChem 2017, 11, 25-47. [CrossRef] [PubMed]

(C) 2020 by the authors. Licensee MDPI, Basel, Switzerland. This article is an open access article distributed under the terms and conditions of the Creative Commons Attribution (CC BY) license (http://creativecommons.org/licenses/by/4.0/). 